PL ISSN 0001-7051

\title{
Mammalian evolution underground. The ecological-genetic-phenetic interfaces
}

\author{
Eviatar NEVO
}

Nevo E. 1995. Mammalian evolution underground. The ecological-genetic-phenetic interfaces. [In: Ecological genetics in mammals II. G. B. Hartl and J. Markowski, eds]. Acta Theriologica, Suppl. 3: 9-31.

The global adaptive convergence of subterranean mammals currently involves 3 orders: rodents, insectivores and marsupials. These include 11 families, 50 genera, and several hundreds of species. This global evolutionary process followed the stepwise climatic cooling and drought followed by biotic extinction in the transition from the middle Eocene to the early Oligocene, a period of 10 million years $(35-45 \mathrm{Ma}=$ million years ago) of profound change in earth geology, climate and biota. The earth changed from the Mesozoic "hot house" to the Neogene (Miocene to Present) "cold house", ie from a warm, equable, mostly subtropical world that persisted from the Mesozoic to the beginning of the present glaciated world. The ecological theater of open country biotas, that opened up progressively in the Cenozoic following the Eocene-Oligocene transition, was associated with increasing aridity, colder climate, and terrestrialism. This climatic change set the stage for a rapid evolutionary play of recurrent adaptive radiations of unrelated mammals on all continents into the subterranean ecotope. The subterranean ecotope is relatively simple, stable, specialised, low or medium in productivity, predictable and discontinuous. Its major evolutionary determinants are specialization, competition and isolation. This ecotope involves the herbivorous (rodents) and insectivorous (insectivores and marsupials) niches. All subterranean mammals share molecular and organismal convergent adaptations to their common unique ecology. By contrast, they display divergent adaptations to their separated niches of herbivory and insectivory and to their different phylogenies. The remarkable adaptive evolution of subterranean mammals involves adaptive structural and functional progression and regression. It is one of the most dramatic examples of global convergent evolution due to underground ecological constraints, at both the molecular and organismal levels of evolutionary theory.

Institute of Evolution, University of Haifa, Mt Carmel, Haifa 31905, Israel

Key words: subterranean mammals, evolutionary convergence, regression, progression

\section{Contents}

The evolution of subterranean mammals: Global tests of convergent, regressive, and progressive evolution

Eocene-Oligocene geological, climatic, and biotic evolution

Adaptive evolution of mammals underground: A testable organismal and molecular model

The ecological background structures

The evolutionary determinants

Specialization

Competition

Isolation

Adaptive molecular and organismal strategies

Ecological patterns 


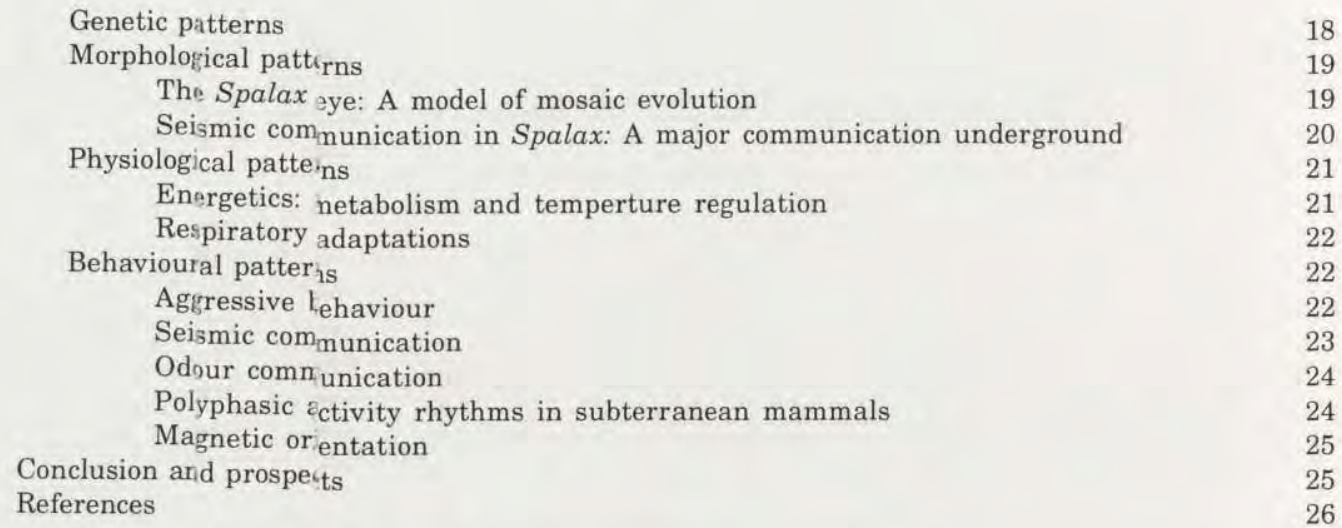

\section{The evolution of subterranean mammals:}

\section{Global tests of convergent, regressive, and progressive evolution}

Global experimønts of convergent evolution, originating due to shared ecological stresses on unrelated taxa, are critical tests of the predictions of evolutionary theory (Nevo 1996). One of the most dramatical experiments of convergent evolution in nature is the evolution of subterranean mammals across the planet (Pearson 1959, Dubost 1968, Nevo 1979, 1991, 1996, Nevo and Reig 1990). This global experiment originated mainly in Oligocene and Neogene times, following drastic world climatic changes of cooling and aridization. These changes have driven representatives of several mammalian orders and families to partial or total life undergrGund. Currently, subterranean mammals involve three orders (marsupials, insectivores and rodents), eleven families, about 50 genera and several hundreds of catalogued species (Figs 1-3).

Chromosomal speciation resulted, however, in mammals generally and particularly in subterrane an mammals, in numerous additional still uncatalogued sibling species. For example, the Israeli classical species Spalax ehrenbergi is a superspecies involving four biological species that evolved during the Pleistocene (Nevo 1991, and references therein). Likewise, in Turkey extensive chromosomal speciation and adaptive radiation of mole rats in the two superspecies, Spalax leucodon $(2 \mathrm{n}=38,40,50,54,60$ and 62$)$, and Spalax ehrenbergi $(2 \mathrm{n}=52,56$ and 58 ) presumably represent from 14 to $>20$ additional biological species (Nevo et al. 1994, 1995). Similar chromosomal speciation resulting in extensive speciation occurred in other spalacids (Savic and Nevo 1990), some geomyids (Nevo et al. 1974), bathyergids (Nevo et al. 1986a), ctenomyids (Reig et al. 1990), and even in talpids (Yates and Moore 1990) and chrysochlorids (Capana et al. 1989, Bronner 1995).

The stressful life underground resulted in diverse adaptive strategies to cope with the unique $\mathrm{pl}_{1 y s i c a l}$ and biotic environmental conditions of the subterranean 


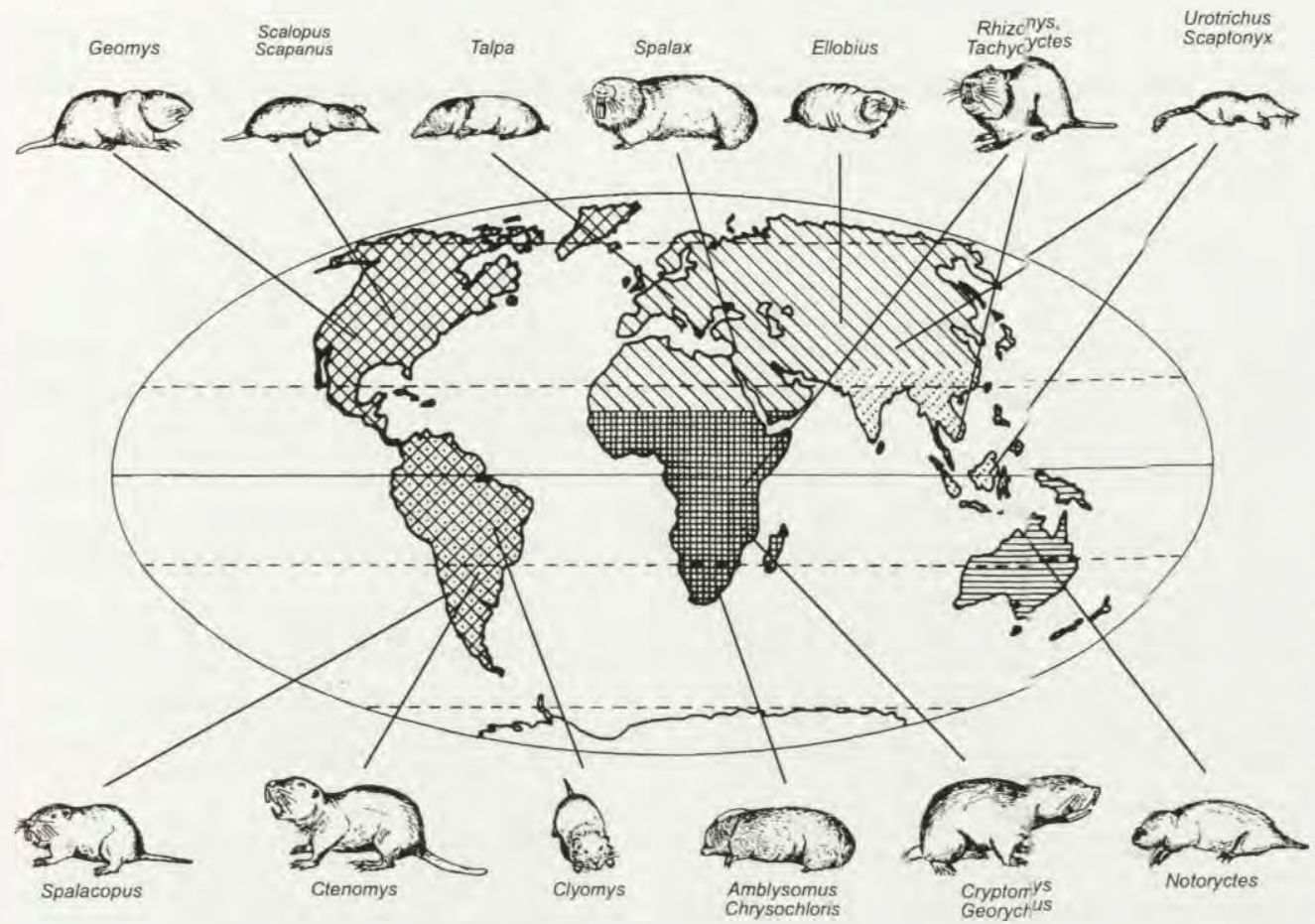

Fig. 1. Distribution of subterranean mammals across the planet. Palaecarcrtic region: Talpa (Talpidae, insectivores), Spalax (Spalacidae, rodents; SE Europe, Turkey, Near East, N Africa) and Ellobius (Arvicolidae, rodents); Ethiopian: Chrysochloris and Amblyson us (Chrysochloridae, insectivores; S Africa), Tachyoryctes (Rhizomyidae, rodents; E Africa), Cryptomys and Georychus (Bathyergidae, rodents; S Africa); Oriental: Scaptonyx and Urotrichus (Talpidae, insectivores; E Asia and Rhizomys (Rhizomyidae, rodents); Australian: Notoryctes (Notoryctidae, marsupial moles); Nearctic: Scalopus and Scapanus (Talpidae, insectivores) and Geomys (Geomyidae, rodents); Neotropical: Spalacopus (Octodontidae, rodents), Ctenomys (Ctenomyidae, rodents), and Clyomys (Echimyidae, rodents). Different hachures mark the different zoogeographical iegions.

ecotope (Nevo 1979, 1990, 1991, 1996, Nevo and Reig 1990). Corivergent evolution in subterranean mammals was intimately connected with regressive evolution of morphological, physiological and behavioural characters, complemented by parallel progressive evolutionary phenomena in all the above organizational levels.

The global and extensive experiment in convergent, both regressive and progressive, evolution of subterranean mammals provides a uniquely fruitful comparative testing model for analyzing the intimate relationships between organism and environment. In particular, it is uniquely fitting for critically testing the "adaptationist programme", the central environmental theory of evolution oriented by natural selection, for structural and functional adaptations to the stressful life underground. These adaptations encompass both the organismal and molecular levels meeting challenges of environmental change, diversity, range and 


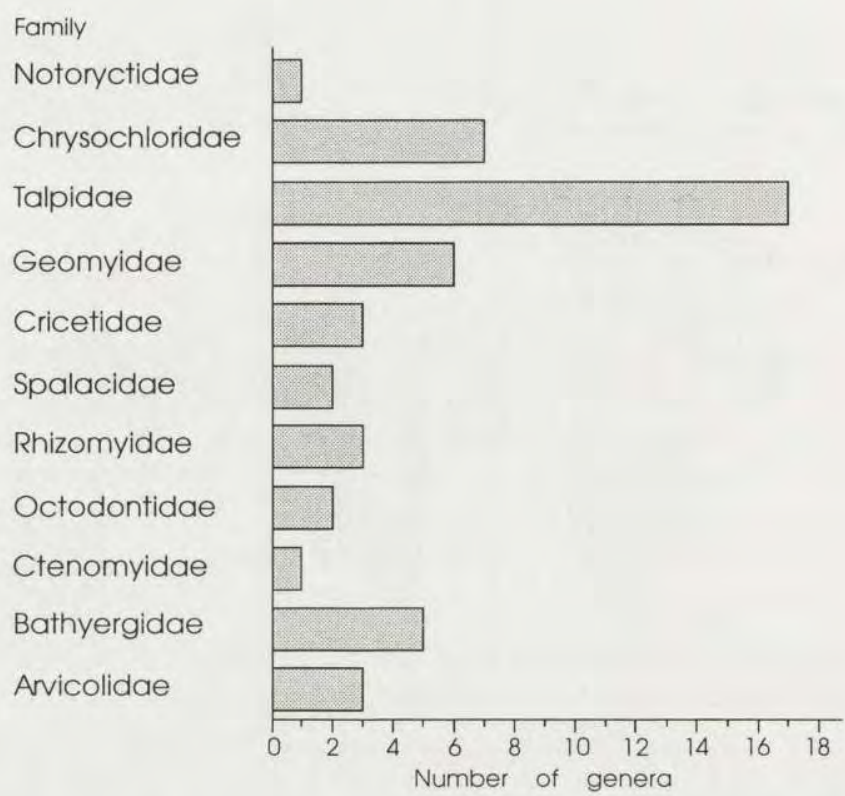

Fig. 2. Tentative number of 50 extant genera in 11 families of subterranean mammals. Systematics varies according to different authors. This graph is based primarily on Nevo and Reig (1990), Anderson and Jones (1984), Corbet and Hill (1991), and recent literature cited in the bibliography.

Family
Notoryctidae
Chrysochloridae
Talpidae
Geomyidae
Cricetidae
Spalacidae
Rhizomyidae
Octodontidae
Ctenomyidae
Bathyergidae
Arvicolidae

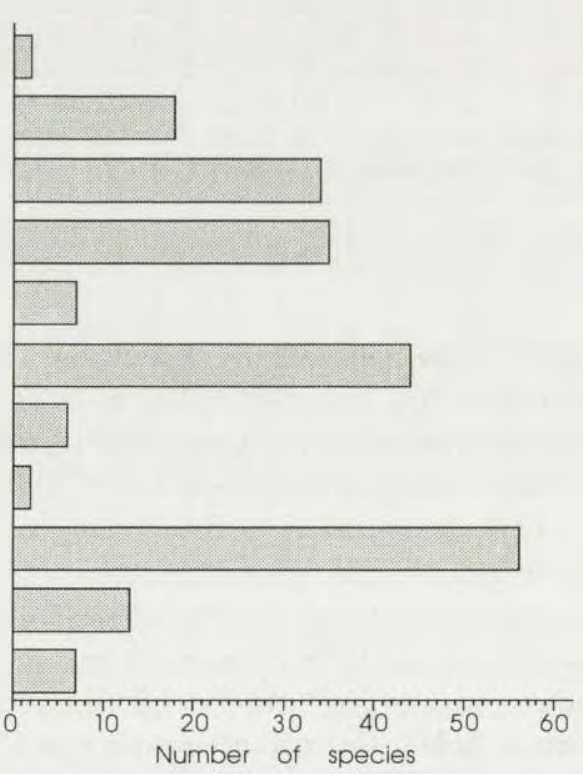

Fig. 3. Tentative number of extant species in 50 genera in 11 families of subterranean mammals. Systematics varies according to different authors. 
stress (eg Nevo 1991, Nevo et al. 1984, Gillespie 1991, Hoffman and Parsons 1991, Parsons 1994).

\section{Eocene-Oligocene geological, climatic, and biotic evolution}

The transition from the middle Eocene to the early oligocene was a period of profound change in earth geology, climate and biota. The earth changed from a warm, equable, mostly subtropical world that persisted from the Mesozoic to the beginning of the glaciated world of today (Prothero and Berggren 1992).

The Eocene-Oligocene transition was gradual, spaced over at least ten million years. The major extinction event took place due to cooling at the middle - late Eocene transition (about 40-41 Ma = million years ago) when warm-humid tropical plants and animals were severely reduced (Prothero and Berggren 1992). This apparent cooling may have resulted from incipient Antarctic glaciation. Lesser extinctions took place at the end of the Eocene ( $34 \mathrm{Ma}$ ), with selective extinction among taxa. In the earliest Oligocene (about 33.5 Ma), there was significant cooling and increase of ice volume. This resulted in major changes in land floras, and

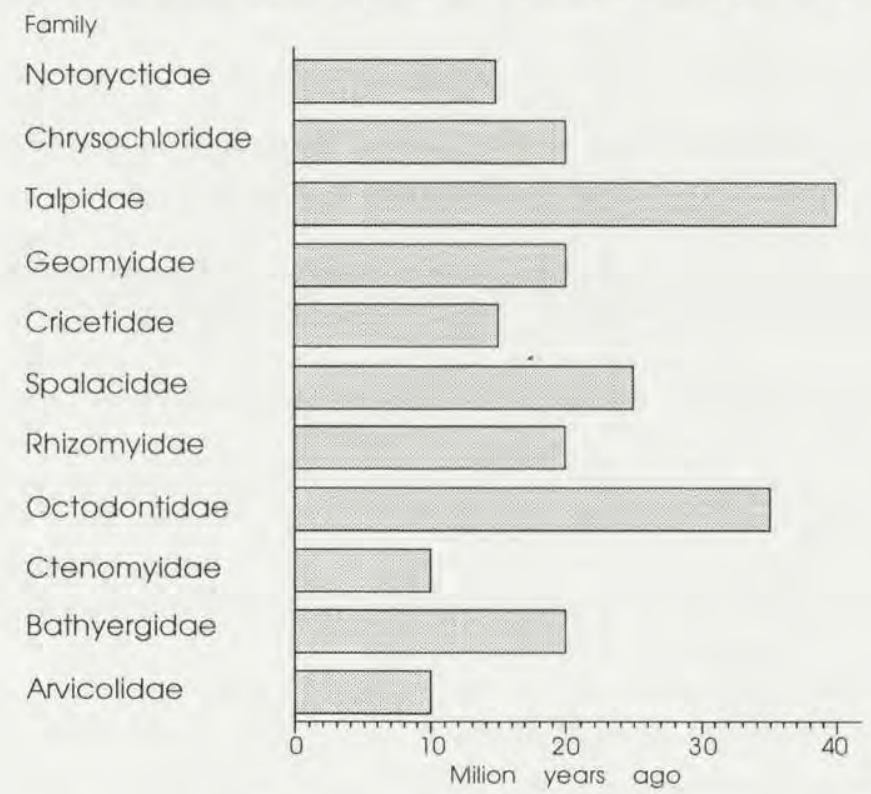

Fig. 4. Geological origin of the 11 families of subterranean mammals based primarily on Anderson and Jones (1984), Nevo and Reig (1990), and references theirein. The earliest known fossils of subterranean mammals are as follows: Notoryctidae (unknown fossils, but Necrolestes from the Miocene is probably a marsupial mole, $\sim 15 \mathrm{Ma}$ ), Chrysochloridae (early Miocene, $\sim 20 \mathrm{Ma}$ ), Talpidae (middle to late Eocene, $\sim 20 \mathrm{Ma}$ ), Geomyidae (early Miocene, $20 \mathrm{Ma}$ ), Cricetidae (middle Miocene, $15 \mathrm{Ma}$ ), Spalacidae (late Oligocene, $25 \mathrm{Ma}$ ), Rhizomyidae (early Miocene, $20 \mathrm{Ma}$ ), Octodontidae (early Oligocene, $\sim 35 \mathrm{Ma}$ ), Ctenomyidae (late Miocene, $10 \mathrm{Ma}$ ), Bathyergidae (early Miocene, 20 $\mathrm{Ma}$ ), Arvicolidae (late Miocene, $10 \mathrm{Ma}$ ). 
possibly the "Grand Coupure" immigration event in European land faunas. Major Antarctic glaciations marked the middle Oligocene (about $30 \mathrm{Ma}$ ), although most aboveground organisms were cold-adapted survivors, and there were relatively few extinctions.

These extinctions were clearly related to climatic change, rather than to extraterrestrial impacts, triggered by the thermal isolation of Antarctica as Australia drifted northward and allowed the developement of deep cold bottom water. In addition, the Cenozoic world orogenies (Andean, Laramide, and Alpine-Himalayan), which started differentially in the Paleogene across the Planet, were reinforced in the Neogene and complemented the global trend of increasing cold, drought, and seasonality.

The Cenozoic ecological theater of open country biota, starting in the Eocene-Oligocene, resulted then from global climatic change, extensive sea regressions, and mountain formation (Webb 1977, 1978, Prothero and Berggren 1992, Janis 1993). The subterranean ecological zone was opened for the global and gradual convergent evolutionary experiment of adaptative radiation underground (Fig. 4). It involved small mammals (herbivores and insectivores) on all continents, excepting Antarctica, thus avoiding the harsh aboveground cooler and drier Oligocene climates (Nevo 1996).

\section{Adaptive evolution of mammals underground: A testable organismal and molecular model}

An evolutionary model, testable at both the organismal and molecular levels, has been proposed by Nevo (1979) and is further elaborated here. The model is summarized here involving the ecological background structures and evolutionary determinants.

\section{The ecological background structures}

The subterranean ecotope is relatively simple, stable, specialized and predictable (Nevo 1979 and references therein). It is presumably poor to medium in productivity and carrying capacity, buffered against intensive predation, and discontinuous in spatial structure. It is essentially fine grained - a mosaic of unequally distributed sparse resources in both space and time. Consequently, massive evolutionary convergence evolved in the subterranean ecotope. The major evolutionary determinants of this convergence are specialization, competition and isolation, both within and between species.

The evolutionary determinants

Specialization

Subterranean mammals adaptively converge on a variety of levels of organization in specialized patterns. Specialization involves genetical, morphological, physiological and behavioural adaptive strategies. These include extensive 
chromosomal speciation, primarily in rodents; relatively low genetic allozymic variation (heterozygosity), cylindrical body, anatomical reductions (of tail, limbs, eyes, ears, etc), and hypertrophies of digging components (eg teeth, forelimbs, depending on taxon; see Fig. 1), vibrissae, brain, stenothermicity and stenohygrobicity, food generalism in both rodents and insectivores, and polyphasic circadian activity patterns. Developed communication modalities of vibration, vocalization and olfaction, replace the atrophy in sight. Populations and species are narrow habitat specialists.

\section{Competition}

Competition for similar resources may favour convergence. This may be particularly true for the subterranean ecotope, where resource competition (which generally takes the form of both intra- and interspecific aggression) is keen. The results of intraspecific competition are (a) solitariness and high teritoriality generated by aggressive behaviour; (b) low-density populations fairly constant and saturated, near to the carrying capacity of their environments; (c) competitive exclusion as an extreme of MacArthur's broken stick model (King 1964); (d) keen competition within and between species increasing with genetic relatedness (Nevo et al. 1986b), and K-strategy (Pianka 1970). K-selection in subterranean mammals favours great competitive ability and overall individual fitness reinforced by a relatively slow development, relatively large size, high longevity and low reproductive rate, food generalism, effective predator escape, and low recruitment and mortality rates. Social evolution is limited and evolved primarily in the bathyergids (Jarvis and Bennet 1990, Sherman et al. 1991).

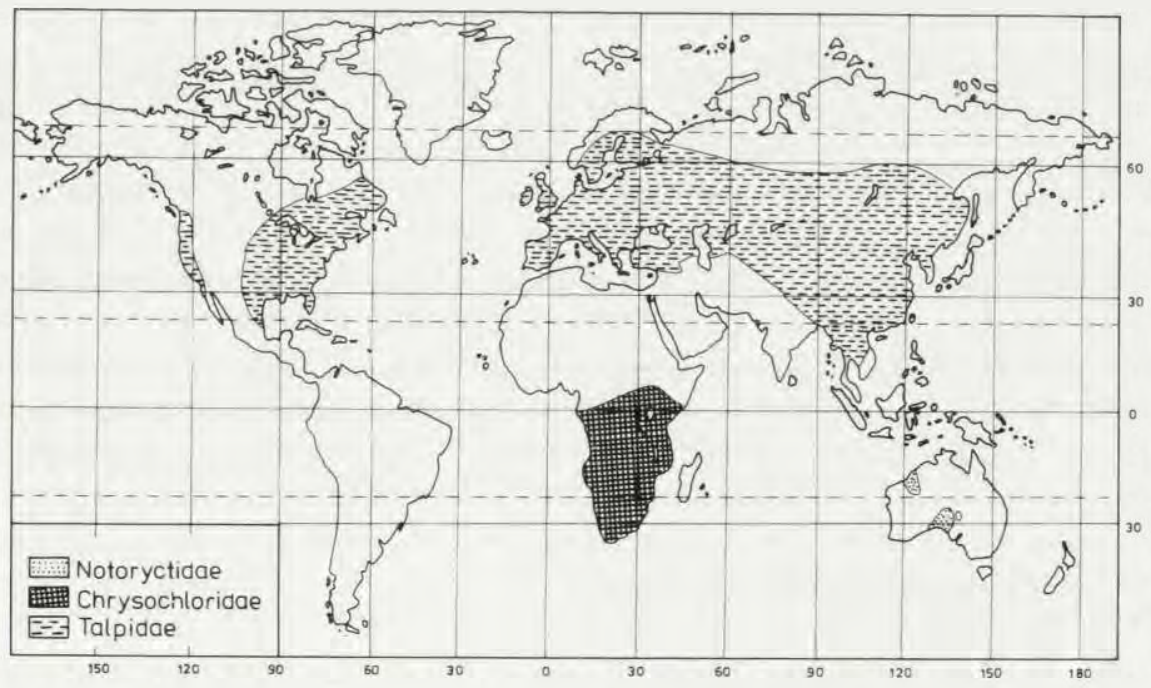

Fig. 5. Distribution of insectivorous subterranean mammals (insectivores and marsupials). From Nevo (1979). 


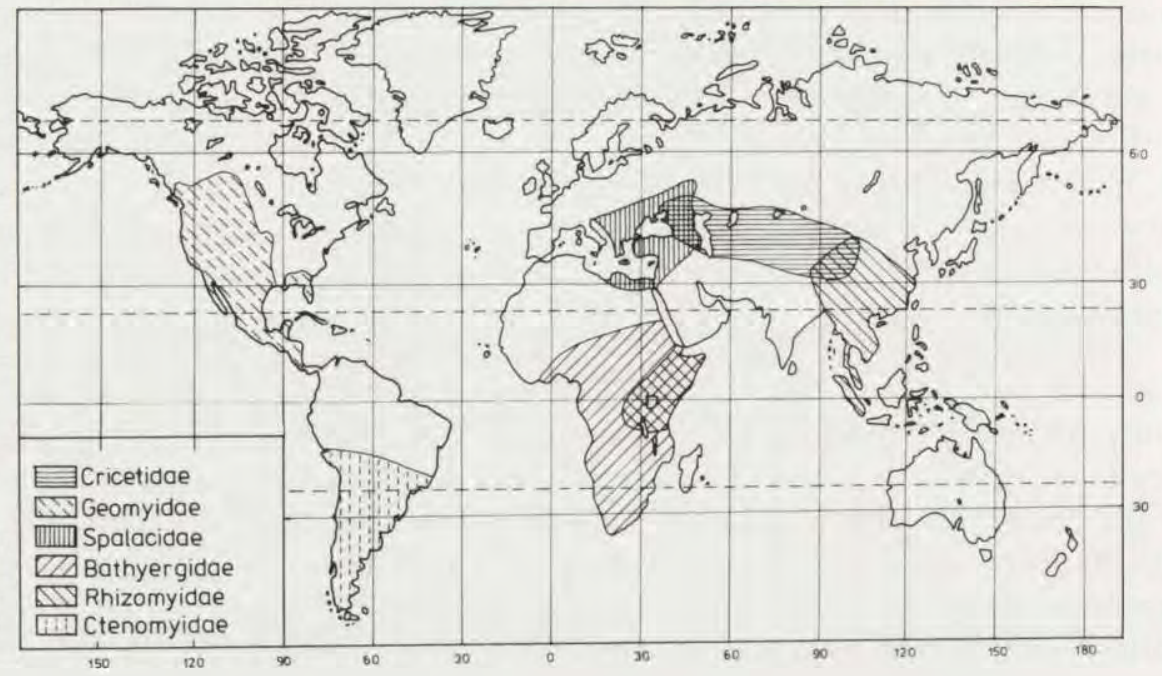

Fig. 6. Distribution of herbivorous subterranean mammals (rodents). From Nevo (1979).

The intense interspecific competition results in largely parapatric distributions, where each species is better adapted to, and more efficient in, its preferred microhabitats. The more finely distinct the competing species are genetically and ecologically, the smaller their zone of geographic or habitat overlap and the sharper their abutting ranges. This pattern supports the niche-overlap hypothesis, which predicts that maximal tolerable niche overlap should decrease with increasing intensity of competition (Pianka 1974). Consequently, species diversity of subterranean mammals in a given area is low, and the species are distributed in specific microhabitats due to climatic diversity aboveground, which is correlated with microclimate underground, and limiting resources. Territoriality within a population, and parapatry or allopatry between species, increase the harvest of food per individual and species. Moreover, because of the low to medium productivity and low carrying capacity, which reflect the amount of limiting resources available per individual, intraspecific competition is keen. Therefore populations are relatively small, subdivided, semi-isolated, and territorially structured (but see Nevo et al. 1982a). The only substantial overlap in subterranean mammals occurs between herbivores and insectivores (see Figs 5 and 6), for which food resources are completely separated. This suggests that distribution is dictated primarily by food rather than competition for space.

\section{Isolation}

The population structure of subterranean mammals discussed above displays emigration patterns supporting the principle of isolation by distance (Wright 1943). 
The degree of emigration, or dispersal, diminishes with distance from a given deme. In its extreme form this is the stepping stone migration model (Karlin 1976). Likewise, gene flow between demes is relatively small due to low vagility, resulting in remarkable local adaptations (eg mitochondrial DNA in Spalax, Nevo and Beiles 1992). Exceptions may involve some subterranean insectivores (Yates and Moore 1990), some rodents (Patton 1990), and colonial Spalocopus (Reig 1970).

Speciation is prolific primarily in subterranean rodents (Nevo 1979, Nevo and Reig 1990, Nevo et al. 1994, 1996) and is greatly facilitated by the population structure and geographic isolation discussed above. Rapid fixation of chromosomal mutations in relatively small populations often results in the evolution of postmating reproductive isolation, which initiates speciation. Premating ethological isolation is superimposed and reinforces postmating reproductive isolation largely in allopatry, incidental to local adaptive differentiation. Hybrids are mostly inferior to parental types reproductively and/or in their viabilities and ecological compatibility. They are, therefore, selectively eliminated, thereby enhancing species formation (Nevo 1991).

The homogeneity of the subterranean habitat dictates geographic speciation. In the resulting pattern, vicarious species, each adapted to local microhabitats, replace each other in space due to continuous or discontinuous (eg on mountain tops) climatic variation. Since the evolving species compete for a fine-grained mixture of similar resources they converge and generalize in their feeding strategies on broad resource curves with extreme interspecific competition leading to competitive exclusion in space. This reinforces species identification and divergence (Nevo 1979, 1991, 1996, Nevo and Reig 1990).

\section{Adaptive molecular and organismal strategies}

Subterranean mammals are highly specialized and adaptively convergent structurally, functionally and behaviourally at all organizational levels to life underground. Nevo (1979) overviewed these strategies and Nevo (1996) expands and elaborates on mammalian evolution underground. The following will be an overview of the convergent and divergent patterns across all extant subterranean mammals (given in Table 1 in Nevo 1979, and Figs 1-3 here).

\section{Ecological patterns}

A convergent ecological syndrome characterizes all subterranean mammals, despite their divergent feeding niches (Nevo 1979, 1996). It involves the following common traits: distribution in the temperate life zone (Figs 5 and 6) regional geographic ranges, relictual endemism; niche specialism, medium habitat productivity, range across several soil types but mainly light ones; special breeding mounds, shallow burrows, multiple feeding mounds per territory, and territoriality. By contrast, a distinctive divergent syndrome separates most subterranean insectivores from rodents. The insectivores feed on animals, primarily inverte- 
brates, whereas the rodents feed mainly on subterranean plant organs (roots, rhyzomes, bulbs, corms), but also on aboveground plant parts (leaves, stems, fruits).

The primary substantial food divergence is associated with insectivory and herbivory (rodents). A distinct syndrome of divergent patterns of interrelated ecological traits is chiefly displayed by the placental insectivores, which comprise most subterranean insectivores (notoryctid marsupials form some distinct exceptions). Placental subterranean insectivores (talpids and chrysochlorids; Figs 1-5) range in mesic, steppic to forest open biotas. They consequently display more regional geographic distribution, more restriction to medium productive habitats, more habitat range generalism, massive sympatry and feeding oportunism. They are more restricted to soil range spectrum (both in number and type of soils), live in shallower burrows, and have by far larger territory sizes to meet their higher metabolic rates (Nevo 1996).

By contrast, subterranean rodents (spalacids, rhizomyids, geomyids, cricetids, arvicolids, octodontids, ctenomyids, bathyergids; see Figs 1-4 and 6) display more widespread geographical ranges, a broader spectrum of habitat range (including both habitat specialists and generalists), ranging over a broader climatic spectrum including arid and subarid climates, displaying distinct allopatry, parapatry, and marginal sympatry but relatively little massive sympatry. They exhibit more feeding specialism, extend over a broader spectrum of soil types, range substantially into xeric, both steppic and desert environments, dig deeper, generate more mounds per territory, and have significantly smaller territory sizes. Clearly, vast underlying intra-ordinal, familial, and generic variances occur in both insectivorous and herbivorous subterranean mammals, but primarily in rodents, as can be clearly seen in the raw data, summary tables and figures (Nevo 1996).

\section{Genetic patterns}

Divergent patterns of chromosome numbers (2n) and fundamental arm numbers (FN) occur among the three orders of subterranean mammals (average and range of $2 n$ : marsupials $-2 n=20$; insectivores $-2 n=34$, range $30-42$; and rodents $-2 n=52$ range, $10-70$ ). However, as indicated above, wide ranges of $2 n$ occur within rodent genera and superspecies. Several families of subterranean rodents, which form most subterranean mammals, converge on high diploid number from $2 \mathrm{n}=54$ to $2 \mathrm{n}=58$.

Subterranean mammals, both insectivores and rodents, converge on low levels of genetic heterozygosity and polymorphism as compared to the mammalian average (Nevo et al. 1984), or to aboveground small mammals (Nevo et al. 1990). The average heterozygosity of subterranean insectivores and rodents, is $H=0.0142$ and 0.037 , respectively (average across both orders $H=0.0308 \pm \mathrm{SE}=0.00373$; $n=45$ ); as against $0.0435 \pm 0.00304, n=111$ of aboveground small mammals (the difference between aboveground, fossorial and subterranean mammals is signifi- 
cant by Kruskal Wallis test: $p=0.0008$, and by Mann Whitney test: $p=0.0002$; Nevo et al. 1990).

\section{Morphological patterns}

A massive morphological syndrome characterizes all subterranean mammals (Dubost 1968, Nevo 1979, 1996). It involves small body size, light body weight, short or absent tail and ear, teeth and/or forelimb developed for digging, largely short claws; progressive stages of eye, and sight degeneration, climaxing in blindness and subcutaneous eyes but functional in light detection (for Spalax see Cooper et al. 1993a, b), predominant presence of baculum, which may display species-specificity (eg Simson et al. 1993), small testes; largely darker pelage colour and dorsal colour matching soil colour. Divergent patterns cut across the subterranean insectivores (primarily forelimb diggers) and rodents (primarily teeth diggers) in digging pattern, sight, snout structure and claw length (Nevo 1979, 1995).

The mosaic evolution of the Spalax eye displays the combined extremes of regressive and progressive evolution in subterranean mammals (Sanyal et al. 1990, de Jong et al. 1990, Cooper et al. 1993a, b, 1995). I will elaborate on this example as a model for structural reductions and hypertrophies which generally characterize subterranean mammals. Likewise, I will overwiev the unique brain reorganization, corroborating seismic communication in Spalax, as a major somatosensory mechanism in adaptive evolution underground.

\section{The Spalax eye: A model of mosaic evolution}

The rudimentary eyes of the mole rat Spalax ehrenbergi are located under the skin (Cei 1946) and do not respond to light stimuli (Haim et al. 1983). However, removal of the eyes disturbs photoperiod perception in these animals (Pevet et al. 1984). To help clarify the possibly remaining function of the eyes in these organisms, we studied their developement and ultrastructure (Sanyal et al. 1990). In the early embryos the presumptive eye regions - the epithelium, lens vesicle, and optic cup - appear initially normal. As developement progresses, the iris-ciliary body complex originates prematurely from the margin of the optic cup and shows a very rapid and massive growth. This pigment-laden tissue mass remains attached to the corneal stroma, obliterates the anterior chamber, and prevents the formation of the corneal endothelium and Descemet's membrane.

In the developing lens the elongation of the lens fibers leads to the formation of a rudimentary lens nucleus that becomes disorganized and vacuolated and eventually also becomes vascularized. This is accompanied by a unique evolutionary change and functional constraints at the molecular level of $\alpha \mathrm{A}$-crystalin (Hendriks et al. 1987). The optic fissure fails to close, the eyes remain colobomatous, and the optic disc appears atrophic. In contrast, retinal histogenesis progresses relatively normally, resulting in structurally reduced, but well-differentiated photoreceptor, neuronal, and ganglion cell layers in the adult eye. Immunohistochemically, the presence of opsin could be demonstrated in the 
photoreceptor cells (de Grip et al. 1992). The latter features may indicate that these rudimentary eyes are still functioning in the complex neuroendocrine pathways mediating photoperiodicity.

The mole rat Spalax ehrenbergi, is an extreme example of natural visual degeneration in mammals: visual pathways are regressed and incomplete (Bronchti et al. 1991), and the absence of visual cortical potentials or an overt behavioural response to light have led to the conclusion that Spalax is completely blind (Haim et al. 1983, Heil et al. 1991, Necker et al. 1992). But structural and molecular investigations of the atrophied subcutaneous eye, suggest a functional role for the retina in light perception (Pevet et al. 1984, Sanyal et al. 1990, De Jong et al. 1990). Entrainment of circadian locomotor and thermoregulatory rythms by ambient light demonstrates a capacity for photoperiodic detection (Haim et al. 1983, Pevet et al. 1984, Heth et al. 1986, Rado et al. 1988, Vuillez et al. 1994, Argamaso et al. 1995). We found that severe regression of thalamic and tectal structures involved in form and motion perception is coupled to a selective hypertrophy of structures subserving photoperiodic functions (Cooper et al. 1993a, b, 1995). The prevalent view that ocular regression results from negative or nonselective evolutionary processes (Brace 1963, Wright 1964, Wilkens 1971) appears wrong. We suggested that the differential reduction and expansion of visual structures in Spalax can be explained as an adaptive response to the dark underground environment (Cooper et al. 1993a, b).

Seismic communication in Spalax: A major communication underground

Seismic, nonvisual communication in mole rats Spalax provides a major somatosensory mechanism in adaptive evolution underground, both in adaptation and speciation (Heth et al. 1987, Rado et al. 1987, Nevo et al. 1991a). The brain mapping of the cortex of Spalax ehrenbergi was explored for somatosensory responses with special reference to an extension into the occipital cortex which serves vision in sighted mammals (Necker et al. 1992). Head and body representation was similar as in other rodents or mammals. However, the somatosensory area extended far into the occipital cortex. No responses to auditory or visual stimulation were found caudal to the somatosensory area. However, auditory responses were recorded in an area lateral to, and slightly caudal to, the head representation. It was concluded that, in this naturally blind animal, the area normally occupied by the visual cortex serves somatosensory function, rather than auditory function as suggested by Heil et al. (1991).

We then extended our exploration into the neuroanatomy of the occipital cortex of Spalax ehrenbergi which was earlier shown to be occupied by a somatosensory representation area (Rehkamper et al. 1994). To date, no visual cortex has been identified electrophysiologically. In order to determine whether there are corresponding modifications in the thalamus, thalamocortical connections were studied with neuroanatomical tracing methods. 
In contrast to the situation in the laboratory rat, in which a prominent dorsolateral geniculate body and ventral lateral geniculate body assume dorsolateral positions, the somatosensory thalamus of the mole rat almost reaches the dorsolateral surface. This finding is corroborated by the results of the architectonic study which failed to reveal a differentiated lateral geniculate body with dorsal and ventral parts. Our observations suggest that the thalamocortical visual system in the mole rat is minute, whereas the somatosensory system is hypertrophied. On average the somatesensory cortex is 1.7 times larger and the VPL/VPM nuclei are 1.8 times larger in the blind mole rat than in the sighted laboratory rat if different body weights are taken into consideration (Mann et al. 1996). This situation fits the biology of this subterranean animal for which touch is more important than sight. The two examples of eye and brain reorganizations in Spalax strongly suggest that expansions or hypertrophies accompany structural reductions in subterranean mammals, following the model of tinkering evolution suggested by Jacob (1977).

\section{Physiological patterns}

Energetics: metabolism and temperture regulation

The energetics of endotherms is influenced by body size, climate, and food habitats (McNab 1979, Contreras and McNab 1990), hence it is adaptive. Low basal metabolic rates (BMR) are shared by desert species and species experiencing poor, periodic, and/or low-energy content foods. On the other hand, high thermal conductances characterize tropical endotherms ( $\mathrm{McNab}$ 1983). The unique subterranean ecotope is characterized by poor and periodic food supply and by atmospheres saturated with moisture. Likewise, metabolism is affected by the digging efforts (Vleck 1979, 1981). The adaptive response to these conditions are reflected in metabolic and respiratory adaptations (Nevo 1979).

Most subterranean rodents share a syndrome of low BMRs, high thermal conductances, high ranges of thermoneutrality, low body temperatures $\left(35-37^{\circ} \mathrm{C}\right)$, and relatively poor thermoregulation. This syndrome is adaptive since it may reduce heat storage and water exchange and minimizes energy expenditure (McNab 1966, 1979, Contreras and McNab 1990). McNab (1979) has suggested that basal rates higher than expected from the Kleiber relation can occur in species larger than $80 \mathrm{~g}$ that live in cool to cold burrows. Low basal rates may also reduce gas exchange in the hypoxic and hypercapnic burrow conditions (Darden 1972).

In contrast, subterranean insectivores have high basal rates and low conductances. These may correlate with their carnivory and may relate to the high cost of predation or to the temporal dependability on soil invertebrates as a food resource. These high rates require a body mass smaller than that of subterranean rodents to reduce overheating in closed burrow systems (McNab 1979, 1983).

Thus, divergent BMRs and thermal conductivity occur in subterranean mammals: insectivores vs rodents. The lower limits of thermoneutrality and most 
(except in chrysochlorids) estimates of minimal thermal conductivity converge in all subterranean mammals.

\section{Respiratory adaptations}

A suite of respiratory adaptations in subterranean mammals evolved as a response to their unique hypercapnic and hypoxic burrow atmospheres, rich in $\mathrm{CO}_{2}$ and poor in $\mathrm{O}_{2}$, respectively. These conditions emerge due to their sealed burrows, oxygen consumption and limited gas permeability (Nevo 1979 and references therein). As described for Spalax (Ar et al. 1977) and other subterranean mammals, including Talpa (Nevo 1979 and references therein). The following adaptive convergent respiratory syndrome characterizes subterranean mammals (see details in Arieli 1990): facilitated gas transport, increased ventilation during hypercapnia, low ventilation response to hypoxia and steep rise at a very low $\mathrm{PO}_{2}$, lower heart rate in hypoxia, as well as resistance to acidosis. These are unique adaptations to hypoxia or stress when high oxygen demand is critical and hypercapnia reduces $\mathrm{pH}$.

Blood and tissue properties also contribute to the adaptive respiratory syndrome (eg Arieli et al. 1986 for Spalax). Blood involves in subterranean mammals high erythrocyte count and small corpuscular volume, both facilitating $\mathrm{O}_{2}$ exchange. Likewise, high $\mathrm{O}_{2}$ affinity of blood facilitates in Spalax $\mathrm{O}_{2}$ loading and unloading in hypoxia, and a better $\mathrm{CO}_{2}$ transport. We have recently concluded for Spalax ehrenbergi that congruent structural adaptations in lung and muscle tissue serve the purpose of living in a hypoxic environment (Widmer et al. 1996). The tissues of subterranean mammals are functionally active at a constant low $\mathrm{PO}_{2}$ and high $\mathrm{PCO}_{2}$. High skeletal-muscle myoglobin content may facilitate $\mathrm{O}_{2}$ diffusion from capillaries to mitochondria. It may represent mammalian convergent physiological adaptation to hypoxic conditions both in high altitudes and underground.

In sum, respiratory adaptations are essential to subterranean mammals to cope with the unique burrow atmospheres underground. Some solutions are convergent, other divergent (see Nevo 1979, 1996 and references therein).

\section{Behavioural patterns}

Subterranean mammals display convergent behavioural syndromes involving: aggressive behaviour, good olfactory communication system and polyphasic circadian activity patterns (Nevo 1996). Regressive evolution of the atrophied eye in extreme cases of subterranean mammals like Spalax was coupled with progressive evolution in a suite of behavioural characters involving seismic and olfaction communication, biorhythmicity and magnetic orientation. Assessment of their development in most other subterranean mammals remain a future challenge.

\section{Aggressive behaviour}

Subterranean mammals are mostly solitary, territorial, and aggressive (Nevo 1979). Aggression is central to Spalax evolution (Nevo et al. 1975, Savic and Nevo 1990). All species and populations of Spalax are polymorphic for aggression, each 
involving trimodal behavioural phenotypes: "pacifists", "intermediates" and "militants". "Pacifism" increases southward from $2 n=52$ to $2 n=60$. We proposed a theory of the evolution of aggression in Spalax based on ecological and genetic premises (Nevo et al. 1986b). We suggested that aggression is affected by resource availability and physiological constraints and predicted that aggression will decline towards and in the desert. Indeed, we have recently found totally pacifistic mole rats in isolates near El Alamein, Egypt (Nevo et al. 1992), suggested as a new species (Nevo et al. 1991b). This supports our evolutionary theory of aggression in Spalax which predicts that aggression should decrease towards the desert, with increased environmental stress (Nevo et al. 1986b), presumably to minimize overheating, water and energy expenditure. This behaviour is a pre-requisite for social evolution. We hypothesized that pacifistic behaviour in Spalax isolates in northern Africa has been adaptively selected for survival in the harsh Sahara desert ecology (Nevo et al. 1992).

\section{Seismic communication}

Vibrational, seismic communication has been extensively described in Spalax (Heth et al. 1987, 1991, Rado et al. 1987, Nevo et al. 1991a). The seismic signals are produced by thumping of the flat head (which originally serves to bulldoze soil and compact the tunnel) against the tunnel ceiling. The seismic signals are temporarily patterned and display a species-specific rhythm of thumping with a low $(\sim 100 \mathrm{~Hz})$ spectral energy that may travel long distances underground between the solitary territorial domains. This contrasts with the short range intra-tunnel domain of vocalization (Nevo 1990). Mole rats communicate vibrationally during agonistic encounters and respond to played-back stimuli (Heth et al. 1987). Field observations (Nevo et al. 1991a) and experiments (Z. Katzir and E. Nevo, in prep.) suggest inter-territorial communication. A dramatic effect occurs between animal introduced to a tunnel and the resident animal. Rich and fast temporal messages, expressing high emotional level, are expressed by the highly aroused mutual thumpings (Z. Katzir and E. Nevo, in prep.).

Seismic communication is an important adaptive strategy in Spalax, assisting in dispersing individuals in space, reducing aggression and partitioning resources effectively. Seismic communication also appears to act as premating isolating mechanism in speciation (Heth et al. 1987, 1991, Nevo et al. 1991a). Thus, underground seismic communication is important in adaptation within populations, in interindividual communication between territories, and in speciation between diverging mole rat populations. Remarkably, as of to day we have not encountered seismic communication in the newly discovered pacifistic Spalax ehrenbergi species ( $2 \mathrm{n}=60$, near El Alamein, north Egypt, which is different in chromosome morphology from the Israeli $2 \mathrm{n}=60$ ) (Nevo et al. 1991b). Drumming on the ground by hind feet in the two solitary bathyergid mole rats, Bathyergus and Georychus (Jarvis and Bennet 1990), display alternative means of seismic communication in subterranean mammals. 


\section{Odour communication}

Odour communication is convergently developed in both insectivorous and herbivorous subterranean mammals, though to different degrees (Burda et al. 1990a, Nevo 1996). Much more critical experiments are needed, like in Spalax, before drawing generalizations (Nevo et al. 1976, 1987, Heth et al. 1992, Menzies et al. 1992). Olfactory discrimination is effectively used in Spalax as an isolating mechanism in speciation. This was experimentally shown when estrous females were attracted to substances in the urine of homospecific, as compared to heterospecific adult males (Nevo et al. 1976). Later, it was shown that estral females are attracted by neutral urine fractions, which apparently contain sex pheromones (Nevo et al. 1987). An active principle, detected in either two or three-choice behaviour tests was extracted from the neutral lipid fraction of the urine, and from male urogenital tissues (Menzies et al. 1992).

Differential olfactory perception of enantiomeric compouds, unrelated to reproductive isolation, was extensively tested in Spalax (Heth et al. 1992). Mole rats respond differentially to odours of steroisomers (enantiomers of carvone, citronellol and fechone), responding to one enantiomer of each tested pair, but displaying indifference to the other one. Various organisms (insects, mammals and humans) discriminate between enantiomeric compounds which differ only in their optical rotation and the speed of their reaction with other chiral molecules (Heth et al. 1992 and references therein). Presumably the differential olfactory perception of enantiomers in Spalax (and possibly in other subterranean mammals) is important in foraging and feeding strategies, ie, in adaptation.

\section{Polyphasic activity rhythms in subterranean mammals}

Subterranean mammals display a convergent pattern of polyphasic activity (active both at day and night) in most insectivores and rodents (Nevo 1979, 1996). Mole rats Spalax have a circadian (24-hour) rhythm (Nevo et al. 1982b). Mole rats proved behaviourally polymorphic for circadian rhytmicity (Ben-Sholomo et al. 1992). Animals comprise of three behavioural phenotypes: (1) regular circadian rhythms, (2) altered-circadian rhythms (shorter or longer than normal), and (3) arhythmic.

Organisms manifest circadian rhythms governed by ill-defined endogenous pacemaker or clock. Apparently, the Drosophila melanogaster period gene product PER is a clock component (Edery et al. 1994). Period-homologous sequence polymorphisms in subterranean mammals were found in the Spalax ehrenbergi superspecies in Israel. They were found to be correlated with call and activity parameters (Ben-Shlomo et al. 1993). We found two different RNAs containing the ACNGGN repeat (prevalent in the PER coding sequence) in the hypothalamus of Spalax. They appear to be more abundant in the non-active (sleeping) phase in general, and may play an important role in circadian rhytmicity (Ben-Shlomo et al. 1994). 


\section{Magnetic orientation}

Magnetic sensitivity, navigation and orientation have been described for diverse organisms across phylogeny including bacteria, insects, fishes and humans (Able 1980, Gould 1984). Compass responses in mammals have been reported in humans (Baker 1980) and the European wood mouse Apodemus sylvaticus (Mather and Baker 1981), despite some contrary evidence (eg Madden and Phillips 1987). Spontaneous magnetic compass orientation was first demonstrated in two subterranean mammals, Cryptomys hottentotus (Burda et al. 1990b) and S. ehrenbergi (Burda et al. 1991). Experimental evidence suggested in both cases that a shift in the magnetic field was followed by relocalizing nests.

The biological significance of spontaneous compass orientation in subterranean mammals is yet unknown. It may assist a subterranean blind mammal in returning to its nest from the peripheral complex burrow network, both in its routine patrolling, and if chased by predators such as snakes. The extent of convergence in magnetic navigation across subterranean mammals is still unknown, though its appearance in a bathyergid and a spalacid suggest a widespread convergence. Likewise, the sensory structural and physiological basis and mechanism(s) involved are unknown in animals in general and in mammals particularly. This cue may assist and complement other nonvisual cues in "tunnel-engineering" in the total darkness of the subterranean environment. The latter is deprived of many stimuli and cues that support orientation aboveground, primarily sight. Future tests and in-depth exploration of magnetic orientation could elucidate the dramatic importance of this cue in adaptive evolution in the unique underground ecotope.

\section{Conclusions and prospects}

The extensive convergent evolution of subterranean mammals across the planet began during the global climatic transition from the middle Eocene to the early Oligocene. It involved cooling, drought and seasonality stresses proceeding progressively throughout the Cenozoic. The ecological theater of open country biota set the stage for a rapid evolutionary play of recurrent adaptive radiations of unrelated mammals on all continents to the subterranean ecotope. These comprise marsupial and placental mammals (both insectivores and herbivores), involving hundreds of mammalian species belonging at present to fifty genera, eleven families and three mammalian orders.

The stressful underground ecotope (darkness, low productivity, hypercapny and hypoxy) provided subterranean mammals with shelter from extreme climatic (temperature and humidity) fluctuations, and predators. All subterranean mammals share convergent molecular and organismal adaptations to their common unique ecotope. By contrast, they display divergent adaptations to their separated feeding niches of herbivory and insectivory and structures derived from their different phylogenies. The subterranean ecotope is simple, relatively stable, 
specialized, low in productivity and discontinuous. Its major determinants are specialization, competition and isolation. These characteristics led to convergent and divergent, regressive and progressive, evolutionary patterns and processes, optimizing adaptations to mammalian life underground.

Adaptive convergence comprise structural and functional reductions and hypertrophies. These involve among other, burrowing and respiratory adaptations affecting molecular, morphological, physiological and behavioural changes as compared with small aboveground mammals. Likewise, life in underground darkness led to the remarkable evolution of photoperiodic perception, affecting circadian rhytmicity through complex mosaic eye and brain evolution. Life underground, in isolated territorial domains, also triggered the evolution of aggression and seismic communication, affecting reorganization of brain architecture. The latter involves the expansion of the somatosensory into the visual cortex, at least in Spalax, but also possibly in other subterranean mammals. Life underground also selected for a suite of adaptive traits to the subterranean ecotope compensating for the progressive loss of sight. These involve vibratory or seismic, magnetic, auditory (discussed in Nevo 1990), chemical, both nasal and vomeronasal, communication systems.

Adaptive convergence also involves intraspecific territoriality and aggressive competition, 24-hour circadian rhytmicity, food generalism, equilibrium populations and K-strategy, low genetic diversity and homoselection, interspecific competitive exclusion and largely parapatric distributions between ecologically and genetically similar species. Adaptive divergence involves alternative patterns in herbivores and insectivores, respectively: large vs small body size; low vs high metabolic rates; high vs low thermal conductances; small vs large territories; small vs high gene flow; high vs low chromosomal speciation and taxonomic diversity. Major phylogenetic differences relate to tooth structure and dietary specialization.

Subterranean mammals provide a uniquely rich evolutionary global tests of speciation and adaptation. Many unresolved evolutionary problems could be elucidated by studying mammalian evolution underground. The main challenge now is to explore convergence at the molecular levels of proteins and DNA and relate it to organismal convergence, as well as to explore convergent brain reorganization. The Cenozoic global experiment of mammalian life underground is a uniquely fruitful field for exploring predictions of evolutionary theory.

Acknowledgements: I thank Drs A. Beiles and L. Blaustein for critically reading this paper. Figs 5 and 6 are reproduced, with permission, from the Annual Review of Ecology and Systematics Vol: 10, 1979, by Annual Reviews Inc. The Israeli Discount Bank Chair of Evolutionary Biology, and the Ancell-Teicher Research Foundation for Genetics and Molecular Evolution established by Florence and Theodore Baumritter of New York supported this research.

\section{References}

Able K. P. 1980. Mechanisms of orientation, navigation and homing. [In: Animal migration, orientation and homing. S. A. Gauthreaux, Jr, ed]. Academic Press, New York: 283-373. 
Anderson S. and Jones J. K., Jr 1984. Orders and families of recent mammals of the world. Wiley Inc., New York: 1-686.

Argamaso S. M., Froehlich A. C., McCall M. A., Nevo E., Provencio I. and Foster R. G. 1995. Photopigments and circadian systems of vertebrates. Biophysical Chemistry 56: 3-11.

Ar A., Arieli R. and Shkolnik A. 1977. Blood-gas properties and function in the fossorial mole rat under normal and hypoxic-hypercapnic atmospheric conditions. Respiration Physiology 30: 102-218.

Arieli R. 1990. Adaptation of the mammalian gas transport system to subterranean life. [In: Evolution of subterranean mammals at the organismal and molecular levels. E. Nevo and O. A. Reig, eds]. Alan R. Liss, New York: 251-268.

Arieli R., Heth G., Nevo E. and Hoch D. 1986. Hematocrit and hemoglobin concentration in four chromosomal species and some isolated populations of actively speciating subterranean mole rats in Israel. Experientia 42: 441-443.

Baker R. R. 1980. Goal orientation by blindfolded humans after long distance displacement: Possible involvement of a magnetic sense. Science 210: 555-557.

Ben-Shlomo R., Ritte U. and Nevo E. 1992. Does period-homologous sequence code for rhytmicity in the mole rat? Israel Journal of Zoology 39: 52.

Ben-Shlomo R., Ritte U, and Nevo E. 1994. RNA with Per-ACNGGN-repeat is cycling in the mole rat brain. Israel Journal of Zoology 40: 93-94.

Ben-Shlomo R., Shin H.-S. and Nevo E. 1993. Period-homologous sequence polymorphisms in subterranean mammals in the Spalax ehrenbergi superspecies in Israel. Heredity 70: 111-121.

Brace C. L. 1963. Structural reduction in evolution. American Naturalist 97: 39-49.

Bronchti G., Rado R., Terkel J. and Wollberg Z. 1991. Retinal projections in the blind mole rat: A WGA-HPR tracing study of a natural degeneration. Developmental Brain Research 58: 159-170.

Bronner G. N. 1995. Cytogenetic properties of nine species of golden moles (Insectivora: Chrysochloridae). Journal of Mammalogy 76: 957-971.

Burda H., Beiles A., Marhold S., Simson S., Nevo E. and Wiltschoko W. 1991. Magnetic orientation in subterranean mole rats of the superspecies Spalax ehrenbergi: experiments, patterns and memory. Israel Journal of Zoology 37: 182-183.

Burda H., Bruns V. and Muller M. 1990a. Sensory adaptations in subterranean mammals. [In: Evolution of subterranean mammals at the organismal and molecular levels. E. Nevo and O. A. Reig, eds]. Alan R. Liss, New York: 269-294.

Burda H., Marhold S., Westenberger T., Wiltschoko R. and Wiltschoko W. 1990b. Magnetic compass orientation in the subterranean rodent Cryptomys hottentotus (Bathyergidae). Experientia 46: $528-530$.

Capana E., Civitelli M. V., Hickman G. C. and Nevo E. 1989. The chromosomes of Amblysomus hottentotus and A. iris (Insectivora, Chrysochloridae). Tropical Zoology 2: 1-12.

Cei G. 1946. Ortogenesi parallela e degradazione degli organi della vista negli spalacidi. Monitore Zoologica Italiano 55: 69-88.

Contreras L. C. and McNab B. K. 1990. Thermoregulation and energetics in subterranean mammals. [In: Evolution of subterranean mammals at the organismal and molecular levels. E. Nevo and O. A. Reig, eds]. Alan R. Liss, New York: 231-250.

Cooper H. M., Herbin M. and Nevo E. 1993a. Ocular regression conceals adaptive progression of the visual system in a blind subterranean mammal. Nature 361: 156-159.

Cooper H. M., Herbin M. and Nevo E. 1993b. Visual system of a naturally micropthalmic mammal: The blind mole rat Spalax ehrenbergi. Journal of Comparative Neurology 328: 313-350.

Cooper H. M., Herbin M., Nevo E. and Negroni J. 1995. Neuroanatomical consequences of microphthalmia in mammals. [In: Vision et adaptation. Y. Christen, M. Doly and M. T. Droy-Lefaix, eds]. Les Séminaires ophtalmologiques d'IPSEN, tome 6, Elsevier, Paris: 127-139.

Corbet G. B. and Hill J. E. 1991. A world list of mammalian species. 3rd. ed. Oxford Univesity Press, Oxford: $1-243$ 
Darden T. R. 1972. Respiratory adaptations of a fossorial mammal, the pocket gopher (Thomomys bottae). Journal of Comparative Physiology 78: 121-137.

Dubost G. 1968. Les mammiferes souterrains. Review Ecology Biology Social 5: 99-197.

Edery I., Rutila E. and Rosbash M. 1994. Phase shifting of the circadian clock by induction of the Drosophila period protein. Science 263: 237-240.

Gillespie J. 1991. The causes of molecular evolution. Oxford Univesity Press, Oxford: 1-336.

Grip W. J., de, Jannsen J. J. M., Foster R. G., Korf H.-W., Rothschild K. J., Nevo E. and de Caluwe G. L. J. 1992. Molecular analysis of photoreceptor protein function. [In: Signal transduction in photoreceptors. P. A. Hargrave, K. P. Hofmann and U. B. Kaup, eds]. Springer-Verlag, Berlin: 43-59.

Gould J. L. 1984. Magnetic field sensitivity in animals. Annual Review of Physiology 46: 585-598.

Haim A., Heth G., Pratt H. and Nevo E. 1983. Photoperiodic effects on thermoregulation in a "blind" subterranean mammal. Journal of Experimental Biology 107: 59-64.

Heil P., Bronchti G., Wollberg Z. and Scheich H. 1991. Invasion of visual cortex by the auditory system in the naturally blind mole rat. NeuroReport 2: 735-738.

Hendriks W., Leunissen J., Nevo E., Bloemendal H. and de Jong W. W. 1987. The lens protein $\alpha \mathrm{A}$-crystallin of the blind mole rat, Spalax ehrenbergi: Evolutionary change and functional constraints. Proceedings of National Academy of Sciences USA 84: 5320-5324.

Heth G., Frankenberg E., Pratt H. and Nevo E. 1991. Seismic communication in the blind subterranean mole rats: Patterns and head thumping and of their detection in the Spalax ehrenbergi superspecies in Israel. Journal of Zoology, London 224: 633-638.

Heth G., Frankenberg E., Raz A. and Nevo E. 1987. Vibrational communication in subterranean mole rats (Spalax ehrenbergi). Behavioral Ecology and Sociobiology 21: 31-33.

Heth G., Nevo E., Ikan R., Weinstein V., Ravid U. and Duncan H. 1992. Differential olfctory perception of enantiomeric compounds by blind subterranean mole rats (Spalax ehrenbergi). Experientia 48: 897-902.

Heth G., Pevet P., Nevo E. and Beiles A. 1986. The effect of melatonin administration and short exposures to cold on body temperature of the blind subterranean mole rat (Rodentia, Spalax ehrenbergi, Nehring). Journal of Experimential Biology 238: 1-9.

Hoffman A. A. and Parsons P. A. 1991. Evolutionary genetics and environmental stress. Oxford University Press, Oxford: 1-284,

Jacob F. 1977. Evolution and tinkering. Science 196: 1161-1166.

Janis C. M. 1993. Tertiary mammal evolution in the context of changing climates, vegetation and tectonic events. Annual Review of Ecology and Systematics 24: 467-500.

Jarvis J. U. M. and Bennet N. C. 1990. The evolutionary history, population biology and social structure of African mole rats: Family Bathyergidae. [In: Evolution of subterranean mammals at the organismal and molecular levels. E. Nevo and O. A. Reig, eds]. Alan R. Liss, New York: 97-128.

Jong W. W., de, Hendriks W., Sanyal S. and Nevo E. 1990. The eye of the blind mole rat (Spalax ehrenbergi). Regressive evolution at the molecular level. [In: Evolution of subterranean mammals at the organismal and molecular levels. E. Nevo and O. A. Reig, eds]. Alan R. Liss, New York: $383-395$

Karlin S. 1976. Population subdivision and selection migration interaction. [In: Population genetics and ecology, S. Karlin and E. Nevo, eds]. Academic Press, Inc., New York: 617-657.

King C. E. 1964. Relative abundance of species and MacArthur's model. Ecology 45: 716-727.

Madden R. C. and Phillips J. B. 1987. An attempt to demonstrate magnetic compass orientation in two species of mammals. Animal Learning \& Behaviour 15: 13-134.

Mann M. D., Rehkämper G., Reinke H., Trahm H. D., Necker R. and Nevo E. 1996. Size of stomatosensory cortex and of somatosensory thalamic nuclei of the naturally blind mole rat, Spalax ehrenbergi. The Journal of Comparative Neurology. (in press) 
Mather J. G. and Baker R. R. 1981. Magnetic sense of direction in woodmice for route-based navigation. Nature 291: 152-155.

McNab B. K. 1979. The influence of body size on the energetics and distribution of fossorial and burrowing mammals. Ecology 60: 1010-1021.

McNab B. K. 1983. Energetics, body size, and the limits to endothermy. Journal of Zoology, London 199: $1-29$

McNab K. 1966. The metabolism of fossorial rodents: A study of fossorial rodents: A study of convergence. Ecology 47: 712-733.

Menzies R., Heth G., Ikan R., Weinstein V. and Nevo E. 1992. Sexual pheromones in lipids and other fractions from urine of the male mole rat, Spalax ehrenbergi. Physiology and Behaviour 52: 741-747.

Necker R., Rehkamper G. and Nevo E. 1992. Electrophysiological mapping of body representation in the cortex of the blind mole rat. NeuroReport 3: 505-508.

Nevo E. 1979. Adaptive convergence and divergence of subterranean mammals. Annual Review of Ecology and Systematics 10: 269-308.

Nevo E. 1990. Evolution of nonvisual communication and photoperodic perception in speciation and adaptation of blind subterranean mole rats. Behaviour 114: 249-276.

Nevo E. 1991. Evolutionary theory and processes of active speciation and adaptive radiation in subterranean mole rats, Spalax ehrenbergi superspecies in Israel. Evolutionary Biology 25: 1-125.

Nevo E. 1996. Evolutionary theory of adaptive progression and regression: The global adaptive convergence of subterranean mammals (in prep.).

Nevo E. and Beiles A. 1992. MtDNA polymorphisms: evolutionary significance in adaptation and speciation of subterranean mole rats. Biological Journal of the Linnean Society 47: 385-405.

Nevo E., Beiles A. and Ben-Shlomo R. 1984. The evolutionary significance of genetic diversity: ecological, demographic and life history correlates. [In: Evolutionary dynamics of genetic diversity. S. Mani, ed]. Lecture Notes in Biomathematics 53: 13-213.

Nevo E., Bodmer M. and Heth G. 1976. Olfactory discrimination as an isolating mechanisms in speciating mole rats. Experientia 32: 1511-1512.

Nevo E., Capanna E., Corti M., Jarvis J. U. M. and Hickman G. C. 1986a. Karyotype differentiation in the endemic subterranean mole rats of South Africa (Rodentia, Bathyergidae). Zeitschrift für Säugetierkunde 51: $36-49$,

Nevo E., Filippucci M. G. and Beiles A. 1990. Genetic diversity and its ecological correlates in nature: Comparison between subterranean, fossorial and aboveground small mammals. [In: Evolution of subterranean mammals at the organismal and molecular levels. E. Nevo and O. A. Reig, eds]. Alan R. Liss, New York: 347-366.

Nevo E., Filippucci M. G., Redi C. D., Korol A. and Beiles A. 1994. Chromosomal and genetic extensive speciation and adaptation: The ecological stress model of subterranean mole rats in Asia Minor. Proceedings of National Academy of Sciences USA 91: 8160-8164.

Nevo E., Filippucci M. G., Redi C., Simson S., Heth G. and Beiles A. 1995. Karyotype and genetic evolution in speciation of subterranean mole rats of Spalax in Turkey. Biological Journal of the Linnean Society 54: 203-224.

Nevo E., Guttman R., Haber M. and Erez E, 1982b. Activity patterns of evolving mole rats. Journal of Mammalogy 63: 453-463.

Nevo E., Heth G., Auffray J. C. and Beiles A. 1987. Preliminary studies of sex pheromones in the urine of actively speciating subterranean mole rats of the Spalax ehrenbergi superspecies in Israel. Phytoparasitica 15: 163.

Nevo E., Heth G. and Beiles A. 1982a. Population structure and evolution in subterranean mole rats. Evolution 36: 1283-1289.

Nevo E., Heth G. and Beiles A. 1986b. Aggression patterns in adaptation and speciation of subterranean mole rats. Journal of Genetics 65 : $65-78$. 
Nevo E., Heth G. and Pratt H. 1991a. Seismic communication in a blind subterranean mammals: A major somatosensory mechanism in adaptive evolution underground. Proceedings of National Academy of Sciences USA 88: 1256-1260.

Nevo E., Kim Y. J., Shaw C. R. and Thaeler C. S., Jr 1974. Genetic variation, selection and speciation in Thomomys talpoides pocket gophers. Evolution 28: 1-23.

Nevo E., Naphtali G. and Guttman R. 1975. Aggression patterns and speciation. Proceedings of National Academy of Sciences USA 72: 3250-3254.

Nevo E. and Reig O. A. (eds). 1990. Evolution of subterranean mammals at the organismal and molecular levels. Alan R. Liss, New York: 1-422.

Nevo E., Simson S., Heth G. and Beiles A. 1992. Adaptive pacifistic behaviour in subterranean mole rats in the Sahara Desert, contrasting to and originating from polymorphic aggression in Israeli species. Behaviour 123: 70-76.

Nevo E., Simson S., Heth G., Redi C. and Filippucci G. 1991b. Recent speciation of subterranean mole rats of the Spalax ehrenbergi superspecies in the El-Hamam isolate, northern Egypt. Proceedings of 6th International Colloquium of Ecology and Taxonomy of small African mammals, 11-16 August 1991, Mizpé Ramon, Israel: 43.

Parsons P. A. 1994. Habitats, stress, and evolutionary rates. Journal of Evolutionary Biology 7 : 387-397.

Patton J. J. 1990. Geomyid evolution: The historical, selective, and random basis for divergence patterns within and among species. [In: Evolution of subterranean mammals at the organismal and molecular levels. E. Nevo and O. A. Reig, eds]. Alan R. Liss, New York: 49-69.

Pearson O. P. 1959. Biology of the subterranean rodent, Ctenomys, in Peru. Memorias dell Museo de Historia Natural "Javier Prado" 9: 1-56.

Pevet P., Heth G., Haim A. and Nevo E. 1984. Photoperiod perception in the blind mole rat (Spalax ehrenbergi, Nehring): involvement of the Harderian gland, atrophied eyes and melatonin. Journal of Experimential Zoology 232: 41-50.

Pianka E. R. 1970. On r- and K-selection. American Naturalist 104: 592-597.

Pianka E. R. 1974. Niche overlap and diffuse competition. Proceedings of National Academy of Sciences USA 71: 2141-2145.

Prothero D. R. and Berggren W. A. (eds) 1992. Eocene-Oligocene climatic and biotic evolution. Princeton University Press, Princeton, New Jersey: 1-567.

Rado R., Gev H. and Terkel J. 1988. The role of light in entertaining the circadian rhythm of the mole rat. Proceedings of 10th International Congress of Photobiology, October 30 - November 5, Jarusalem, Israel: 26

Rado R., Levi N., Hauser H., Witcher J., Adler N., Intrator N., Wolberg Z. S. and Terkel J. 1987. Seismic signalling as a means of communication in subterranean mammal. Animal Behaviour 35 : 1249-1266.

Rehkamper G., Necker D. and Nevo E. 1994. Functional anatomy of the thalamus in the blind mole rat Spalax ehrenbergi: An architectonic and electrophysiologically controled tracing study. Journal of Comparative Neurology 347: 570-584.

Reig O. A. 1970. Ecological notes on the fossorial octodontid rodent Spalacopus cyanus (molina). Journal of Mammalogy 51: 592-601.

Reig O. A., Busch C., Ortells M. O. and Contreras J. R. 1990. An overview of evolution, systematics, population biology, cytogenetics, molecular biology and speciation in Ctenomys. [In: Evolution of subterranean mammals at the organismal and molecular levels. E. Nevo and O. A. Reig, eds]. Alan R. Liss, New York: 71-96.

Sanyal S., Jansen H. G., de Grip W. G., Nevo E. and de Jong. W. W. 1990. The eye of the blind rat, Spalax ehrenbergi: Rudiment with hidden function. Investigative Ophthalmology \& Visual Science 31: 1398-1404. 
Savic I. R. and Nevo E. 1990. The Spalacidae: Evolutionary history, speciation and population biology. [In: Evolution of subterranean mammals at the organismal and molecular levels. E. Nevo and O. A. Reig, eds]. Alan R. Liss, New York: 129-153.

Sherman P. W., Jarvis J. U. M. and Alexander R. 1991. The biology of the naked mole rat. Princeton University Press, Princeton, New Jersey: 1-518.

Simson S., Lavie B. and Nevo E. 1993. Penial differentiation in speciation of subterranean mole rats Spalax ehrenbergi in Israel. Journal of Zoology, London 229: 493-503.

Vleck D. 1979. The energy cost of burrowing by the pocket gopher Thomomys bottae. Physiological Zoology 52: 122-136.

Vleck D. 1981. Burrow structure and foraging cost in the fossorial rodent Thomomys bottae. Oecologia 49: 391-396.

Vuillez P., Cooper C. H. M., Herbin M., Nevo E. and Pevet P. 1994. Photic induction of Fos-immunoreactivity in the suprachiasmatic nuclei of the blind mole rat (Spalax ehrenbergi). Brain Research 654: 81-84.

Webb S. D. 1977. A history of savanna vertebrates in the New World, Part I. Annual Review of Ecology and Systematics 8: 355-380.

Webb S. D. 1978. A history of savanna vertebrates in the New World, Part II. Annual Review of Ecology and Systematics 9: 393-426.

Widmer H. R., Hoppeler H., Nevo E., Taylor C. R. and Weebel E. R. 1996. Respiratory adaptations to survival underground in the blind subterranean mole rat. (in press)

Wilkens H. 1971. Genetic interpretation of regressive evolutionary processes: Studies on hybrid eyes of two Astyanax cave populations (Characidae, Pisces). Evolution 25: 530-544.

Wright S. 1943. Isolation by distance. Genetics 28: 114-138.

Wright S. 1964. Pleiotropy in the evolution of structural reductions and of dominance. American Naturalist 98: 65-69.

Yates T. L. and Moore D. W. 1990. Speciation and evolution in the family Talpidae (Mammalia: Insectivora). [In: Evolution of subterranean mammals at the organismal and molecular levels. E. Nevo and O. A. Reig, eds]. Alan R. Liss, New York: 1-22.

Received 22 May 1995, accepted 15 August 1995. 